Revista Iberoamericana, Vol. LXX, Núm. 206, Enero-Marzo 2004, 103-115

\title{
BAJO LAS ALAS DEL ÁNGEL DE CARIDAD: INDIGENISMO Y BENEFICENCIA EN EL PERÚ REPUBLICANO
}

\author{
POR \\ Ana Peluffo \\ University of California, Davis
}

Una de las preocupaciones, y casi se podría decir obsesiones de la cultura latinoamericana del siglo XIx, fue la creación, a nivel de los imaginarios, de comunidades homogéneas que pudieran percibirse como orgánicamente nacionales. Doris Sommer en Foundational Fictions (1991) demuestra cómo en las novelas fundacionales decimonónicas se utilizó una retórica erótico-amorosa para tratar de representar en el orden simbólico, y por medio de complejos desplazamientos metonímicos, la tan deseada cohesión nacional. Dado que la heterogeneidad étnico-cultural es percibida como debilitadora y problemática, en el período modernizador positivista, me interesa explorar la posibilidad de que no sólo el amor-eros, del que habla Sommer, haya sido utilizado como una herramienta alegórica para forjar la identidad nacional, sino también el amor-ágape. Por amor-ágape entiendo un tipo de afecto sentimental, no erótico, asociado con la caridad cristiana, que fue utilizado en la cultura latinoamericana del siglo XIX para regular la interacción entre las diversas etnias, regiones y clases.

En el caso particular del Perú, el discurso de la caridad republicana se articula con una cuestión sumamente debatida en el período post-bélico de la guerra del Pacífico (1879-1883). Me refiero al concepto de la virtud (derivado de vir-hombre), que como tantos otros términos de este período resultó ser sumamente elástico y ambiguo. ${ }^{1}$

En una época de crisis, en la que González Prada definía la nación en términos apocalípticos, a través de la metáfora de la pus: “El Perú es un órgano enfermo, donde se aplica el dedo brota pus” (46) , cobra particular importancia la oposición entre el ser y el deber ser nacional. ¿Cuáles serían los valores alrededor de los que se forjaría la idea de la peruanidad? ¿Cuáles iban a ser los grupos encargados de encarar el proyecto modernizador? Si bien en toda la literatura producida en esta época, tanto desde el centro como desde la periferia de la ciudad letrada, se le asignó a la madre republicana el rol de inculcar la virtud nacional en los futuros ciudadanos, no estaba tan claro qué tipo de virtud debía irradiar esta figura desde el espacio doméstico del hogar. ¿Era una virtud marcial y clásica asociada con el valor y el coraje, o había que propiciar una ética más cristiana y humanitaria relacionada con el ámbito sentimental y “femenino” de las emociones? Es interesante contrastar a este

\footnotetext{
${ }^{1}$ La genealogía del concepto de la "virtud" junto con el proceso de feminización al que se lo somete en la cultura victoriana ha sido estudiada por Ruth Bloch en "The Gendered Meanings of virtue in Revolutionary America”.
} 
respecto las respuestas de Clorinda Matto de Turner y de Manuel González Prada ante esta crisis provocada por una derrota bélica que, como apunta sagazmente Antonio Cornejo Polar, demostró, no sólamente "la obvia debilidad militar" del Perú frente a Chile sino también "la muy endeble constitución de la sociedad peruana, su desintegración sin atenuantes y el fracaso sustancial de los distintos, pero muy parecidos, proyectos nacionales que habían sido asumidos hasta entonces por las diversas (aunque también muy parecidas) fracciones de la clase dirigente” (Clorinda Matto de Turner novelista, 55).

La lección que González Prada extrae de la guerra es que había que revivir un modelo heroico de masculinidad ya que sólo la virtud guerrera podía salvar a la república. Dice en 1888, en el ensayo del Politeama, leído en el teatro del mismo nombre:

Verdad, hoy nada podemos, somos impotentes, pero aticemos el rencor, revolvámonos en nuestro despecho como la fiera se revuelca en las espinas y si no tenemos garras para desgarrar ni dientes para morder, ¡qué siquiera los mal apagados rugidos de nuestra cólera viril vayan de cuando en cuando a turbar el sueño del orgulloso vencedor! (48)

Si el sujeto nacional soñado se construye en este discurso alrededor de la figura de un valiente soldado, capaz de morir heroica y virilmente por una idea de nación, ${ }^{2}$ en los textos de Clorinda Matto de Turner se vislumbra por esta misma época un tipo de ciudadano más humanitario que patriótico, que pueda ejercer las virtudes altruistas de la filantropía. La alternativa que Matto postula, en Aves sin nido (1889) y en Bocetos al lápiz de americanos célebres (1889), a la figura del héroe militar de González Prada es la de la dama de caridad. La virtud sentimental que practicaba este personaje podía ser construida a su vez como una especie de maternalismo social ya que, desde su espacio doméstico asignado, el ángel del hogar extendería sus alas sobre otros grupos excluidos de los proyectos nacionales, en este caso los indios, ante los cuales las clases más altas debían, según Matto, asumir un rol proteccionista y a-culturador. Más que la revancha nacionalista contra Chile, Matto de Turner propone en estos textos sentimentalizar el concepto hegemónico de nación recurriendo a los preceptos cristianos de la beneficencia.

El discurso de la caridad fue percibido como apropiado para armonizar o mediar las virtudes políticas y domésticas alrededor de las cuales se construía la subjetividad en el siglo xix. La palabra caridad, que deriva del latín y significa amor, se asocia con un sentimiento altruista que fue utilizado en el período republicano para contrarrestar las desigualdades creadas por el avance de la modernización. Gordon Wood, dentro del campo historiográfico norteamericano, ha demostrado cómo en una rama marginal del pensamiento de la ilustración se exaltaron los valores sentimentales de la benevolencia que no parecían incompatibles con el énfasis que la época de las luces colocó en la razón. Según

\footnotetext{
${ }^{2}$ A tono con la marcada francofilia de González Prada, el sujeto nacional imaginado para salvar la república es, en este ensayo, un soldado francés más que latinoamericano. En varios pasajes se compara desfavorablemente a los ejércitos indígenas de la Guerra del Pacífico con las tropas de la Revolución Francesa: “Con las muchedumbres libres, aunque indisciplinadas de la Revolución, Francia marchó a la victoria; con los ejércitos de indios disciplinados y sin libertad, el Perú irá siempre a la derrota. Si del indio hicimos un siervo, ¿qué patria defenderá? Como el siervo de la Edad media, sólo combatirá por el señor feudal” (44).
} 
los pensadores de "la escuela del sentido moral" (Hutcheson, Shaftesbury), la caridad es un afecto que se origina en el ámbito privado del hogar pero que, un poco a la manera del famoso lema "la caridad bien entendida empieza por casa", se extiende en círculos concéntricos hasta abarcar espacios públicos cada vez más englobantes y alejados del yo. ${ }^{3}$ Según Wood, es la desaparición de la relación colonial entre súbdito y monarca lo que provocó, a fines del siglo xviII y principios del siglo xix, la resurrección del concepto cristiano de la caridad como una forma de cimentar y unir entre sí a los diversos miembros del cuerpo nacional. ${ }^{4}$ El problema con este concepto sentimental de la nación como una familia extendida, en la que las clases más altas sienten compasión por las clases oprimidas fue, tal y como acertadamente lo señala Wood, articularlo con los postulados supuestamente fraternales e igualitarios del republicanismo liberal. ${ }^{5}$ En el fondo, el modelo de nación cristiano basado en la benevolencia no dejaba de ser jerárquico, porque se configuró como “una comunidad imaginada” regida por una lógica de intercambio, en la que las clases subalternas respondían con gratitud al paternalismo benevolente de las élites.

En el caso del sujeto femenino republicano, la ideología de la benevolencia tuvo en sus orígenes alcances inesperados, y hasta en algún sentido radicales, que desestabilizaron las categorías topográficas de lo público y lo privado alrededor de las cuales se organizaba la cultura republicana. En Women and the Work of Benevolence: Morality, Politics and Social Class in the Nineteenth-Century United States (1990) Lori Ginzberg señala que el discurso de la benevolencia, aparentemente conservador y esencialista con respecto a la cuestión de género, fue utilizado por el sujeto femenino victoriano de Nueva Inglaterra para ensanchar los límites de la esfera doméstica, y para crear diversos movimientos de reforma cultural. ${ }^{6}$ Destaca, en este sentido, el caracter contradictorio de una ideología que se basaba a nivel discursivo en una separación imaginada entre las esferas de la moral y la política, categorías que en la vida cotidiana no estaban tan claramente diferenciadas. La creencia de que la caridad era un atributo femenino, derivado de la mayor capacidad afectiva del “sexo débil” fue, según Ginzberg, una extensión de la ideología de la

\footnotetext{
${ }^{3}$ Francis Hutcheson y Anthony Shaftesbury son los principales representantes de la "escuela del sentido moral". Para Hutcheson, el sentido moral es un sexto sentido que impulsa al individuo a actuar virtuosamente. El sentido moral forma parte de la conciencia moral del individuo que le sirve para distinguir moralmente entre las acciones buenas y las malas.

${ }^{4}$ Ver a este respecto el capítulo titulado "Benevolence” de Gordon S. Wood, en The Radicalism of the American Revolution (213-25).

${ }^{5}$ Jorge Basadre utiliza la frase oximorónica, "república aristocrática”, formada por dos términos antinómicos para diferenciar el proyecto republicano peruano del norteamericano en el período que va de 1895 a 1919. Como lo demuestra Ricardo Portocarrero esta frase es particularmente apropiada para resaltar la naturaleza contradictoria de este concepto de nación, moldeado según elementos aristocráticos tradicionales asociados con el proyecto civilista. Ricardo Portocarrero, "La república aristocrática” En: Portocarrero, Castro. Entre la república aristocrática y la patria nueva.

${ }^{6}$ Ginzberg cita entre las campañas de reforma moral emprendidas por el sujeto femenino decimonónico los programas en contra del juego, la prostitución y el alcoholismo, así como también las campañas anti-esclavistas de las sufragistas. Se forma así por medio de las actividades de beneficencia una cultura periférica a la masculina cimentada por lazos de género en la que las mujeres adquieren un rol político como "purificadoras" del espacio nacional.
} 
maternidad republicana, en la que las mujeres accedían a la categoría de la ciudadanía por medio de la influencia moral que ejercían sobre futuros ciudadanos. ${ }^{7}$ Tanto el discurso cultural de la maternidad como el de la caridad contribuyeron a la formación de la clase media, generando la noción de que la virtud sentimental, más que la riqueza material, era la base sobre la que había que fundar el bienestar y el progreso. ${ }^{8}$ Paradójicamente, el discurso altruista que colocó al sujeto femenino en una órbita doméstico-afectiva sirvió, no solamente para justificar su exclusión de espacios alejados del hogar y de la iglesia sino también, para convertir el hogar en un espacio de poder desde el cual emprender las primeras críticas a los proyectos de la modernización. Desde una perspectiva conservadora, la creencia de que las mujeres eran más compasivas y benevolentes que los hombres sirvió para justificar la subordinación de un género al otro, en el marco de una jerarquía que colocaba lo cerebral-racional por encima de lo afectivo-sentimental.

El caracter fronterizo e híbrido que detecta Ginzberg en el discurso de la filantropía (a caballo entre la moralidad y la política) se pone de relieve en varias novelas latinoamericanas del siglo xix, en las que se parodia o se celebra a la dama de caridad. En Las consecuencias (1889) de Mercedes Cabello de Carbonera, novela basada en una tradición titulada “Amor de madre” de Ricardo Palma, la señora Alvarado, madre de la heroína, es una mujer activa en el campo de la beneficencia. Lo que se demuestra en esta novela es que el ejercicio de la caridad podía servir no solamente para transgredir la tenue frontera entre lo doméstico y lo político, sino también para que el sujeto femenino obtuviera a nivel público un cierto tipo de visibilidad. Dice el sujeto literario sobre esta venerable señora:

A las doce del día recibía en un pequeño saloncito (no en el del rocambor) á crecido número de mujeres pobres, que iban á su casa, las unas á recibir alguna pequeña mesada, otras á demandar un extraordinario socorro, y todas un consuelo á su mísera condición. A esta hora la casa tenía tanto movimiento como el despacho de un Ministro de Hacienda. (Cabello de Carbonera, Las consecuencias 15)

En este pasaje, el sujeto femenino consigue emprender, amparado en la práctica de la caridad, actividades extra-estatales que le permiten construirse una identidad política sin transgredir los estrechos límites de su esfera. La posibilidad que tenían las mujeres de

\footnotetext{
7 Sobre la ideología de la maternidad republicana se puede consultar: Kerber, Linda. "The Republican Mother: Women and the Enlightenment-An American Perspective”.

${ }^{8}$ Otra contribución importante al debate sobre los conflictos de clase y género que atraviesan el constructo ficticio de ángel del hogar en la cultura victoriana es la de Elizabeth Langland en Nobody's Angels (1995). Langland coincide con Ginzberg en que el ángel del hogar tuvo un rol importante en la consolidación de los valores de la clase media, que buscó diferenciarse a lo largo del siglo xix de los vicios de la aristocracia y el proletariado. Para Langland, la relación dama de caridad-proteger que tiene lugar en el ámbito público es una proyección de la relación ángel del hogar-criada que ocurre dentro del hogar. En el caso de Matto de Turner, la relación dama de caridadindígena está moldeada de acuerdo al discurso afectivo de la maternidad republicana. El indígena, más que en calidad de criado, es incorporado a la familia-nación como un hijo adoptivo que necesita ser protegido y amado por una madre que lo adopta impulsada por la caridad.
} 
utilizar el discurso de la caridad como velo dependía de que se subrayaran las implicancias sentimentales de la beneficencia, y de que se obliteraran los alcances político-económicos de esta práctica. Como bien lo apunta Ginzberg, aunque se suponía que la caridad era una actividad desinteresada, que se realizaba por amor al prójimo, encubría privilegios de clase que daban a estas mujeres acceso a grandes cantidades de dinero. En este sentido, no solamente era importante que se obliteraran los aspectos pecuniarios de la beneficencia sino que nunca se la practicara de forma profesional o militante. Un ejemplo del exceso que podía generar el activismo caritativo se materializa en Blanca Sol (1889) de Mercedes Cabello de Carbonera, novela en la que se reproducen voces dominantes que criticaban a las damas de caridad por la forma en que el activismo filantrópico las alejaba de la prescripción maternal-doméstica. En su calidad de heroína-monstruo, Blanca Sol es una versión caricaturesca de la dama de beneficencia, que practica la caridad de forma individualista y anti-sentimental para vencer el ennui de la domesticidad. ${ }^{9}$ Dice el sujeto literario que Blanca Sol era presidenta de numerosas hermandades y sociedades de beneficencia, y que lo hacía, no por verdadero amor al prójimo, sino para “disipar el hastío que embargaría su espíritu en las horas que no eran de visitas ni de recepciones” (Blanca sol 34).

En Bocetos al lápiz de americanos célebres, (1889) una colección de perfiles biográficos que Matto publica con fines prescriptivos didácticos, se propone a "la señora de Pucuto”, cuyo verdadero nombre era Ana María Centeno de Romainville como máximo modelo de virtud republicana. El perfil de esta dama de caridad cusqueña, a quien Matto compara por sus virtudes caritativas con Mary Carpenter y San Vicente de Paul, ya había aparecido en Tradiciones cusqueñas, biografías y hojas sueltas (1884). El hecho de que Matto decidiera re-editar este perfil en 1889 hace pensar que consideraba a este personaje como una figura-joya dentro de una larga cadena de biografías emblemáticas. La razón por la que Matto asocia a esta dama cusqueña con figuras renombradas de la caridad europea se hace evidente en varios tableaux sentimentales del perfil en los que "la señora de Pucuto” aparece, como una madre Teresa del siglo XIX, ayudando a los indígenas desamparados y enfermos. Vale la pena citar el siguiente pasaje:

Cuando en 1855 infestó el Departamento del Cuzco la terrible peste que hasta hoy es recordada con dolor, los pobres indios eran los que formaban la mayor suma de las víctimas, pues se veían, al decir de los que nos cuentan, chozas llenas de cadáveres: familias enteras perecían sin auxilio de ningún género, I es entonces cuando la señora Centeno, como otra hija de San Vicente de Paul, iba de rancho en rancho medicinando a los enfermos, consolando a los moribundos I recogiendo a los pobres huérfanos que quedaban sin más providencia que “la señora de Pucuto”. (209) ${ }^{10}$

\footnotetext{
${ }^{9}$ Yolanda Martínez-San Miguel estudia la construcción de Blanca Sol de acuerdo a la categoría de la monstruosidad en "Sujetos femeninos en Amistad funesta y Blanca Sol: El lugar de la mujer en dos novelas latinoamericanas de fin de siglo XIX".

${ }^{10}$ Todas las citas de este perfil pertenecen a Tradiciones Cusqueñas. Leyendas, biografías y hojas sueltas. Municipalidad del Cusco: Cusco, 1997.
} 
En esta viñeta, el heroísmo de la señora de Pucuto se recorta contra una masa anónima de cuerpos indígenas cuya humanidad colectiva deriva de su capacidad de sufrir y experimentar dolor. Al mismo tiempo, la autoridad de la dama de caridad está anclada en la figura de un indio mudo cuya experiencia de marginalidad debe ser traducida a palabras. En el encuentro con la otredad racial es la mujer criolla la que se convierte en voyeuse de los padecimientos de los indios y en testigo sentimental de sus infortunios. La pasividad de los indígenas es inversamente proporcional al activismo de la señora de Pucuto, que iba, medicinaba y consolaba a las víctimas del avance de una modernidad concebida en términos europeos. La revelación de los suplicios que experimentan los indios sirve para poner al descubierto los defectos colectivos de un proyecto de nación, deficiente o distópico, que necesita ser corregido por el lector imaginado. La señora de Pucuto hace un trabajo necesario en la comunidad nacional que las autoridades no quieren hacer, en parte por temor al contagio, y en parte porque las vidas de los indios tienen un valor más económico que humanitario en el proyecto liberal.

Lo que demuestra Matto de Turner en este perfil es que a fines del siglo xix, cuando el Estado todavía se encontraba en estado rudimentario, eran las mujeres las que estaban efectuando un trabajo social que en el siglo xx se va a profesionalizar (léase masculinizar) en forma de ministerios de bienestar social, o centros de salud pública. Si la señora de Pucuto deriva su autoridad en la comunidad andina del sufrimiento de un otro colonial, al que responde con el ejercicio de virtudes humanitarias, la escritura de la semblanza puede ser leída asimismo como un acto filantrópico. Para generar el bien de la nación, Matto debe subrayar la orfandad metafórica del indio y hacer que el lector sienta la necesidad de "adoptarlo" al seno de una nación concebida como una gran familia. La propuesta humanitaria-filantrópica de Matto de Turner parece haber perdido vigencia en el siglo xx frente a otras explicaciones socio-económicas sobre "el problema del indio", como la de Mariátegui, que tal vez por eso excluye a Clorinda Matto de Turner de sus Siete ensayos de interpretación de la realidad peruana (1928). Pese a que Clorinda Matto interpreta "el problema del indio" (la frase es de Mariátegui) más en términos morales que socio-económicos, me parece importante historizar su propuesta y leerla en el contexto de otros proyectos de nación en los que se le asigna al indio un espacio cercano a una barbarie que hay que eliminar o superar para entrar en la modernidad. La deshumanización del indio contra la que Matto reacciona aparece en otros textos de la época en los que se barbarizan las diferencias étnicas para justificar la eliminación de aquél del proyecto nacional. Así por ejemplo, en un texto de viaje titulado Travels in South America, Paul Marcoy, escritor y etnógrafo que según Matto vivió un tiempo en la finca de la señora de Pucuto, construye literariamente a los indios como seres malolientes y degradados, que sufren de "hidrofobia" o aversión al agua, añadiendo que de sus cuerpos, llenos de parásitos, se desprende un desagradable olor. Cito:

Indians go from the cradle to the grave without having felt for one moment the need of washing their face and hands. This sufficiently accounts for the parasites which infest them, and for that sickly odor which so unpleasantly counterbalances in the eyes of the artist the picturesque side of their nature. (242) 
La ambivalencia de Marcoy ante el sujeto indígena, al que coloca, ya del lado de lo asqueroso, ya del lado de lo pintoresco, es similar a la de escritores peruanos, como González Prada o Ricardo Palma, que pese a que elaboran por esta misma época proyectos de nación antitéticos coinciden en la visión del indígena como un obstáculo para el progreso. Dentro de este contexto etnocéntrico, la propuesta filantrópica cristiana de Clorinda Matto, que humaniza al indígena apelando a su capacidad de sufrir, fue una propuesta bastante más radical para su época de lo que sus detractores del siglo xx están dispuestos a concederle.

Desde un punto de vista biográfico, es interesante notar que a lo largo de su vida Clorinda Matto de Turner combina el desempeño de la profesión intelectual con el ejercicio de obras de caridad. Manuel Cuadros en Paisaje y Obra dice que al morir Clorinda Matto de Turner deja estipulado en su testamento que:

[...] de la venta de su libro, "Viaje de Recreo" se aplique, una parte, para dotar completamente a la criatura mujercita, que ingrese en la Cuna de los huérfanos el día de su fallecimiento, y otra parte sea enviada al Cuzco para aplicarla al Hospital de Mujeres de su ciudad natal. (147)

La literatura como profesión le permite a Matto financiar proyectos de caridad concebidos como actos de reforma social, sólo que aquí la preocupación por la identidad de género se superpone a la de raza. En el prólogo a Leyendas y recortes, Joaquín Lemoine celebra el abnegado patriotismo caritativo de la autora cuzqueña, que transforma durante la guerra del Pacífico su hogar de Tinta en "hospital de sangre”. Dice Lemoine que Clorinda Matto de Turner:

Recibió allí en los brazos a sus hermanos armados heridos por el plomo enemigo y rociados por las perlas que diluviaban sus ojos. Los valientes oficiales y soldados [...] son testigos de la abnegada filantropía de esa hermana de la caridad patriótica. (Lemoine XXXVII)

La imagen que emerge aquí de Matto de Turner es curiosamente similar a la de "la señora de Pucuto” ya que los cuerpos de los soldados heridos, a los que atendía, y sobre los que "vertía lágrimas”, eran en su mayor parte indios, como es casi de rigor en las guerras de Latinoamérica, y como lo apunta Jorge Basadre para la guerra del Pacífico en La iniciación de la República (98-99). Tanto en el caso de Clorinda Matto, como en el de la señora de Pucuto, los esfuerzos caritativos funcionan en casos aislados (el de la huerfanita a la que Matto le cede las ganancias de su libro, el de los indígenas que tenían la suerte de recibir los auxilios humanitarios de la señora cuzqueña) pero no son efectivos a nivel colectivo. No sólo que la señora de Pucuto sólo consigue recoger a unos pocos indios en su finca sino que a su muerte éstos vuelven a su situación desgraciada inicial.

El discurso de la caridad se articula a su vez con una forma sentimental de reaccionar ante los problemas nacionales ya que lo que despierta los sentimientos benevolentes del sujeto femenino es el sufrimiento del subalterno. El énfasis en la situación desesperada de los indios que lloran, sufren, se enferman y mueren es un arma ideológica que apela a la 
conmiseración del lector. A nivel estético, es una propuesta que nos resulta difícil de digerir en el siglo xx, en el que el sentimentalismo exagerado que raya en el melodramatismo, nos parece de mal gusto. Tópicos como la orfandad, la enfermedad y la viudez prematura, caros al sentimentalismo decimonónico, están presentes en este perfil, en el que la narración de vida de la dama de caridad se estructura alrededor de una serie de muertes (la de la madre, la del padre, la del esposo) que van dejando a la dama de Pucuto en una situación curiosamente similar a la de los indígenas huérfanos que recoge en su hogar. Se trata de establecer así, por medio del énfasis en los padecimientos de los grupos golpeados por el liberalismo (mujeres-indios), una relación de hermandad fundada en el poder de las lágrimas, y en la creencia de que el sufrimiento puede derribar barreras de género, raza y clase. ${ }^{11}$ Sin embargo, me interesa subrayar que la idealización de los lazos sentimentales que se establecen entre la dama de caridad criolla y los indios encubre las diferencias abismales, no sólamente materiales, sino también culturales que los separan. Al convertir al indio en objeto de piedad de una dama de caridad, se produce en el texto un claro silenciamiento de la voz del otro que se convierte en un objeto mudo, fácilmente interpretable por el sujeto femenino. La relación entre superior (dama de caridad) e inferior (indios) que se plantea no deja de ser jerárquica porque el indio para salvarse necesita de un otro, que está por encima de él, y que decide qué es lo que se le debe dar o quitar. Al mismo tiempo, pese a que en el texto se subraya que la caridad de la señora de Pucuto es completamente desinteresada, una afirmación que por lo insistente termina resultando sospechosa, se especifica también que la señora cuzqueña recibe una retribución nomaterial de parte de los indios, que no sólamente riegan a su muerte el féretro con sus lágrimas, sino que movidos por un “cariño agradecido” hacen una colecta para construirle una placa recordatoria en el cementerio. La máxima recompensa a la abnegación y a la filantropía en la tierra le llega a la señora de Pucuto en el cielo, cuando la voz narradora describe su entrada a un paraíso, tan real y tangible como la finca de Pucuto. Dice el sujeto literario:

Llegó el momento en que la caritativa señora fuese a recibir el galardón de manos del Creador, y, sonriendo tal vez desde la mansión de los que practicaron el bien, presenció el dolor que su partida había causado a todas las clases sociales. (210)

La fascinación necrológica, casi macabra, de este texto con las escenas de muerte y de duelo, descritas siempre desde el punto de vista de los que quedan, los huérfanos, es una diferencia cultural con nuestro siglo (en el que la muerte es tabú) que no se puede subrayar suficientemente. El espacio del hogar, que en tantas novelas decimonónicas aparece como un recinto sagrado en el que las clases ilustradas se aislan de una peligrosa exterioridad se convierte en este perfil en un lugar que mantiene una relación de ósmosis con la otredad, un centro de asistencia pública, en este caso un orfelinato, en el que la nación es representada sinecdóquicamente por los indios huérfanos y enfermos que necesitan ser rehabilitados por el trabajo social de la dama de caridad. La relación

\footnotetext{
${ }^{11}$ He desarrollado este tema en el ensayo "El poder de las lágrimas: Sentimentalismo, género y nación
} en Aves sin nido de Clorinda Matto de Turner". 
metonímica entre hogar y nación se complejiza porque las virtudes domésticas de la hospitalidad que practica la señora de Pucuto con los indios se extienden también a una serie de viajeros extranjeros (Paul Marcoy, el conde de Castelneau) que llegaban a esta finca "edeniana” atraídos por una "colección de antigüedades peruanas i dijes de valor inestimable” (210). Aquí, aparece en el perfil el entusiasmo que los letrados del siglo xix experimentan con respecto al pasado, una preocupación que paradójicamente coincidió en el período nacional con la exaltación de la ideología del progreso. La colección de arte indígena, que la señora de Pucuto llega a amasar con fervor religioso, es descrita por Matto como la mejor del Perú, opinión que según ella corroboran Paul Marcoy y el conde de Castelneau en dos libros de viaje publicados en este período. ${ }^{12}$ El profesionalismo de la señora de Pucuto como curadora es elogiado por Matto, que lo describe como "una de aquellas pasiones caprichosas que casi rayan en locura”, y que llega hasta tal punto que en los últimos días de su vida "manifestó el deseo de que su cadáver fuese depositado en el salón de sus antiguedades, mientras lo trasladaban al Cementerio” (210) La mención de este museo se conecta con el impulso indigenista de este texto que no sólamente busca mostrar la condición deplorable de los indígenas en el presente, sino que intenta hacer una recuperación arqueológica de su pasado. Ante la pregunta historiográfica de cuál debía ser el origen de la identidad nacional que se planteó en el XIx, Matto responde que había que hacer arrancar el sentimiento de lo nacional del período del Incanato, sin que esa idealización le impidiese ver el caracter aniquilado, desheredado y pobre del indio en el presente. Esta propuesta puede leerse en contrapunto con la de Ricardo Palma, que fundaba el origen de la peruanidad en el hispanismo de la época colonial, y en una oralidad limeña más que cuzqueña o andina. La finca de Pucuto se convierte entonces, por un lado, en un espacio en el que se buscan conciliar los diferentes elementos que constituyen la nacionalidad; y por otro, en un teatro o plataforma en el que la señora de Pucuto desarrolla identidades múltiples y contradictorias. A través de roles como el de dama de caridad, curadora y empresaria (porque de alguna manera esta señora viuda administraba su dinero para poder efectuar labores de caridad) el discurso de Matto reproduce, al mismo tiempo que amplía y cuestiona, los discursos normativos de la femineidad republicana. La señora Centeno es madre, pero ejerce sobre los indios un tipo de maternidad no biológica sino social; es dama de caridad, pero ese rol le permite justificar actos de desobediencia social fuera del hogar; y por último, es educadora ya que al igual que Clorinda Matto, la señora de Pucuto organiza veladas literarias para convertir su hogar en un centro de ilustración a la manera de una "salonniere" francesa. ${ }^{13}$

El fetichismo coleccionista de la señora de Pucuto que busca reconstruir el pasado por medio de la acumulación de objetos antiguos se presta también a una lectura autobiográfica. Así como el sujeto biográfico preserva en su museo de arte indígena artefactos culturales que representan metonímicamente una tradición andina amenazada por el avance de un proyecto modernizador citadino, Clorinda Matto colecciona en sus Tradiciones cuzqueñas

\footnotetext{
${ }^{12}$ He buscado referencias a la colección de antigüedades peruanas de la señora de Pucuto en los libros de viaje de Marcoy y de Castelnau pero no he encontrado todavía ninguna mención a este museo. ${ }^{13}$ Sobre la actuación del sujeto femenino decimonónico en el ámbito de las veladas literarias ver: Graciela Batticuore; así como también, Francesca Denegri.
} 
anécdotas referentes a los monumentos, campanas, paisajes e iglesias de una región olvidada del Perú. Incluso sus compendios biográficos pueden ser leídos como “colecciones” de vidas en las que Matto demuestra que no sólo la vida militar y guerrera, regida por un concepto clásico de la virtud, merece ser inmortalizada. Dentro del proyecto historiográfico de Matto de Turner cualquier vida, por insignificante que parezca, puede tener el derecho de pasar a la historia. En el caso de esta vida en particular, Matto se fascina no sólamente por la forma en que esta señora acata y subvierte al mismo tiempo la idea normativa de la domesticidad, sino también, por el hecho de que es una vida que está a punto de desaparecer del archivo biográfico republicano. La preocupación por el estado de anonimato al que puede acceder este personaje histórico aparece obsesivamente en el micro-perfil y se condensa en la intención de narrar una vida, no sólamente para proponerla como modelo de virtud, sino también para que "no se pierda en la oscuridad de los tiempos”. (192)

A manera de contraste, es interesante traer a colación aquí las opiniones abiertamente negativas que tiene González Prada por esta época sobre la caridad en sus proyectos de modernización y progreso. Dice que las mujeres practican la caridad por "snobismo", "desocupación” o "novelería” y que los hombres que colaboran en estas empresas son “afeminados”, “débiles”, “anémicos de sangre y bolsa”. (263) La caricatura que hace Prada de la dama de caridad, preocupada por las apariencias y por darse ínfulas de gran dama, muestra que las actividades caritativas de estas mujeres, que salían (del hogar) para combatir el vicio en nombre de la virtud, generaron un cierto nivel de ansiedad. Esta visión negativa del activismo femenino en el campo de la beneficencia se articula con un deseo por parte de la cultura hegemónica de racionalizar la caridad haciendo que no se alejara demasiado de la casa. En el caso de Prada, esto se suma a un anticlericalismo furibundo y a una visión de la dama de caridad como esclava y aliada de la clerecía. Dice en "Nuestros conservadores":

Todas las cofradías y hermandades ostensiblemente fundadas con fines humanitarios o piadosos sirven de cuarteles generales al clero para conservar y extender su dominación eterna y temporal. (264)

Las damas de caridad son vistas por Prada como siervas de la iglesia, y los sacerdotes como enemigos domésticos del hogar porque se interponen, a través de la práctica de la confesión entre las mujeres y los maridos, y porque poseen sus almas y a veces sus cuerpos (237). Curas y mujeres forman para González Prada una contra-cultura sentimental, aferrada a la tradición católica, que él percibe como hostil a los avances de la modernidad. Sin embargo, esta relación que González Prada ve como aproblemática y homogénea se convierte en la literatura de Matto de Turner en un espacio conflictivo. La dama de beneficencia y el sacerdote compiten, más que colaboran, por la titularidad del rol de artífices de la caridad, y por el prestigio de velar por la suerte de los grupos marginales. La excomunión de Clorinda Matto por parte de la iglesia luego de la publicación de Aves sin nido (1889) se fundó sobre todo en la representación despiadada de los curas como seres moralmente degradados que explotan a los indios y acosan sexualmente a las mujeres. En los textos de Matto de Turner, la visión del sacerdote como una figura 
hiperbólicamente negativa y oscura le sirve a la autora para exaltar, en un marcado claroscuro, la figura de la dama de beneficencia asociada con una claridad (caridad) que es preciso irradiar en su propuesta de progreso. En este sentido la "señora de Pucuto" parece ser un doble de la heroína de Aves sin nido, Lucía Marín, que también recurre al discurso de la caridad para justificar un activismo político que le estaba vedado en el siglo XIX al ángel del hogar. El discurso de la caridad se invoca entonces en los momentos de mayor transgresión de la novela cuando Lucía decide transgredir su lugar doméstico asignado (la idea de que "la mujer ha nacido para poetizar la casa") para salir en defensa de los indios. Dice:

En nombre de la Religión cristiana, que es puro amor, ternura y esperanza; en nombre de vuestro Maestro que nos mandó dar todo á los pobres, os pido, señor cura, que déis por terminada esa deuda que pesa sobre la familia de Juan Yupanqui. ¡Ah! Tendréis en cambio doblados tesoros en el cielo... (Aves sin nido 42)

La figura del cura Pascual, al que la sociedad le asigna erróneamente el rol de difundir los mandamientos cristianos, le permite a la dama de caridad brillar por cuenta propia en el ejercicio de las virtudes humanitarias. El argumento piadoso de Lucía apela a la lógica mercantil de las autoridades (porque practicar la caridad es una forma de asegurarse la entrada al paraíso) al mismo tiempo que provoca en la comunidad una batalla entre los representantes del vicio y de la virtud concebida en términos de una "guerra de los buenos contra los malos”. Cabe señalar, en este sentido, que la intervención caritativa de Lucía es exitosa en el caso aislado de las dos niñas huérfanas o "aves sin nido" que decide acoger en su nido a la muerte de sus padres, pero tiene efectos desastrosos para los padres indios de esas mismas niñas (Juan y Marcela Yupanqui) que mueren como consecuencia de su intervención. Se puede decir entonces que en los textos de Matto de Turner se elogia el impulso caritativo a nivel individual, al mismo tiempo que se reconocen sus deficiencias y limitaciones a nivel colectivo.

La valorización conflictiva que hace Matto de la benevolencia como ingrediente regenerador y homogeneizador de la nación la acerca más a la concepción sentimental de la virtud que tiene José Martí que a la iconografía anti-sentimental que prevalece en los ensayos de Manuel González Prada. Así Martí, en un cuento infantil titulado “La muñeca negra”, publicado en La edad de oro (1885), representa metonímicamente a la virtud por medio de una niña, llamada Piedad, que entre todas sus muñecas prefiere a la negra porque nadie la quiere. También en "Nuestra América”, texto preocupado por la falta de cohesión de los pueblos latinoamericanos, José Martí planteaba la necesidad de unificar a los diversos sectores por medio de la caridad. "El genio hubiera estado en hermanar", dice Martí, "con la caridad del corazón y con el atrevimiento de los fundadores, la vincha y la toga; en desestancar al indio; en ir haciendo lado al negro suficiente; en ajustar la libertad al cuerpo de los que se alzaron y vencieron por ella” (Martí 124). En realidad, lo que plantea Martí en este pasaje es que para construir naciones fuertes que pudieran hacer frente a los avances del vecino del norte, había que recurrir a los dos tipos de virtud, a la virtud clásica del patrimonio marcial y a la cristiana asociada con la caridad. A través del personaje anónimo de "la señora de Pucuto” quien, al igual que Lucía, se deja conmover 
por la tragedia de un otro racial en peligro, Matto redefine el concepto de la virtud republicana eliminando todo vestigio de la acepción marcial. Si por medio del acatamiento del amor-ágape se consigue politizar al ángel del hogar y domesticar el concepto masculino de la virtud guerrera, no se logra, sin embargo, darle estatus de sujeto al indio, que necesita para vencer el inmovilismo trágico de su situación cambios radicales a nivel socio-económico más que la compasión de la dama de caridad.

BiBLIOGRAFÍA

Basadre, Jorge. La iniciación de la república. Tomo primero. Lima: F y E Rosay, 1929. Batticuore, Graciela. El taller de la escritora: Veladas literarias de Juana Manuela Gorriti: Lima-Buenos Aires (1876/7-1892). Buenos Aires: Beatriz Viterbo editora, 1999.

Bloch, Ruth. “The Gendered Meanings of Virtue in Revolutionary America”. Signs: Journal of Women in Culture and Society 13 (1987): 37-58.

Cabello de Carbonera, Mercedes. Las consecuencias. Lima: Imprenta de Torres Aguirre, 1889.

Blanca Sol. (Novela Social). 2da. edición. Lima: Imprenta y librería del Universo de Carlos Prince, 1889.

Castelneau de, Francis. Histoire du Voyage. Expedition dans les parties centrales de l’Amerique du Sud, de Rio de Janeiro a Lima, et de Lima au Para. 1851.

Cornejo-Polar, Antonio. Clorinda Matto de Turner novelista. Estudios sobre Aves sin nido, Indole y Herencia. Lima: Lluvia editores, 1992.

"La literatura hispanoamericana del siglo xix: Continuidad y ruptura (Hipótesis a partir del caso andino)”. La imaginación histórica en el siglo XIX. Lelia Area y Mabel Moraña, eds. Rosario: UNR editora, 1994.

Cuadros, Manuel. Paisaje y obra......Mujer e historia: Clorinda Matto de Turner. Cuzco: H.G. Rozas, 1949.

Denegri, Francesca. El abanico y la cigarrera. La primera generación de mujeres ilustradas en el Perú. Lima: Flora Tristán, 1996.

Ferrater Mora, José. Diccionario de filosofía. Madrid: Alianza Editorial, 1980.

Ginzberg, Lori. Women and the Work of Benevolence: Morality, Politics, and Class in the Nineteenth-Century United States. New Haven: Yale University Press, 1990.

González Prada, Manuel. Páginas libres/Horas de lucha. Caracas: Biblioteca Ayacucho, 1976.

Hutcheson, Francis. On Human Nature. Thomas Mautner, ed. New York: Cambridge University Press, 1993.

Kerber, Linda. “The Republican Mother: Women and the Enlightenment-An American Perspective”. American Quarterly 28 (1976): 187-205.

Langland Elizabeth. Nobody's Angels. Middle-Class Women and Domestic Ideology in Victorian Culture. Ithaca: Cornell University Press, 1995. 24-61.

Lagarrigue, Juan Enrique. La religión de la humanidad. Santiago de Chile: Imprenta Universitaria, 1947. 
Lemoine, Joaquín. “Clorinda Matto de Turner”. Matto de Turner, Clorinda. Leyendas y recortes. Lima: Imprenta La Equitativa, 1887.

Marcoy, Paul. Travels in South America from the Pacific Ocean to the Atlantic Ocean. Vol 1. New York: Scribner, Armstrong \& Co., 1875.

Mariátegui, José Carlos. Siete ensayos de interpretación de la realidad peruana. Lima: Amauta, 1963.

Martí, José. La edad de oro. México: Fondo de Cultura Económica, 1995.

Martínez-San Miguel, Yolanda. "Sujetos femeninos en Amistad funesta y Blanca Sol: El lugar de la mujer en dos novelas latinoamericanas de fin de siglo xix”. Revista Iberoamericana 174 (1996): 27-45.

Matto de Turner, Clorinda. Aves sin nido. Novela peruana. Valencia: F. Sempere y Compañía, 1889.

Bocetos al lápiz de americanos célebres. Lima: Peter Bacigalupi editores, 1889. Tradiciones cusqueñas. Leyendas, biografías y hojas sueltas. Municipalidad del Cusco: Cusco, 1997.

Peluffo, Ana. “El poder de las lágrimas: Sentimentalismo, género y nación en Aves sin nido”. Moraña, Mabel, ed. Indigenismo hacia el fin del milenio. Homenaje a Antonio Cornejo Polar. Pittsburgh: IILI-Biblioteca de América, 1998.

"El indigenismo como máscara: Antonio Cornejo Polar ante la obra de Clorinda Matto de Turner”. Antonio Cornejo Polar y los estudios culturales latinoamericanos. Friedhelm Schmidt-Welle, ed. Berlin: Ibero-Amerikanisches Institut PK, 2001 (en prensa).

Portocarrero, Castro. Entre la república aristocrática y la patria nueva. Lima: Sur, Derrama magisterial, 1996.

Prochaska. F. K. Women and Philantropy in Nineteenth-Century England. Oxford: Clarendon Press, 1980.

Sommer, Doris. Foundational Fictions. The National Romances of Latin America. Berkeley: University of California Press, 1984.

Shaftesbury, Anthony. Characteristics of Men, Manners, Opinions, Times... Lawrence E. Klein, ed. Cambridge: Cambridge Univ. Press, 1999.

Wood, Gordon S. The Radicalism of the American Revolution. New York: Alfred A. Knopf, 1992. 